\title{
Can Hume Deny Reid's Dilemma?
}

\author{
ANTHONY NGUYEN
}

\begin{abstract}
Reid's dilemma concludes that, whether the idea associated with a denied proposition is lively or faint, Hume is committed to saying that it is either believed or merely conceived. In neither case would there be denial. If so, then Hume cannot give an adequate account of denial. I consider and reject Powell's suggestion that Hume could have advanced a "Content Contrary" account of denial that avoids Reid's dilemma. However, not only would a Humean Content Contrary account be viciously circular, textual evidence suggests that Hume did not hold such an account. I then argue that Govier's distinction between force and vivacity cannot help Hume. Not only did Hume fail to recognize this distinction, we can advance a variant of Reid's dilemma even if we distinguish force from vivacity.
\end{abstract}

\section{Introduction}

Notoriously, David Hume had ambitious plans to do much with very little. In particular, he wielded impressions, ideas, and a few principles concerning them to great effect. With such sparse resources, Hume claimed to have demonstrated that "[w]e have . . no idea of substance" (T.1.1.6.1; SBN 16); that "[t]here is no object, which implies the existence of any other" (T.1.3.6.1; SBN 86); that "[w]e have no other notion of cause and effect, but that of certain objects, which have been always conjoined together" (T.1.3.6.15; SBN 93, Hume's emphasis); and much else besides. ${ }^{1}$

Given such ambitions, it is no wonder that much of Hume's philosophy is disputed. I will focus on an important but often overlooked topic in Hume scholarship: Hume's treatment of 
denial - the positive rejection of a claim or proposition. Not only would Hume's philosophical system be unacceptable if it could not accommodate such a quotidian propositional attitude, but there is theoretical fruit for Hume to reap if he can capture denial. As Lewis Powell notes, Hume can simply treat "affirming a conjunction [as] a conjunction of affirmations" (8n19). But then much rests on Hume's ability to adequately treat denial: "[G]iven a proper account of negative contents and conjunctive contents, one can recursively define an account of all other logical connectives" (Powell, 22). ${ }^{2}$ It is important to Hume's philosophical program that he can adequately treat denial.

But a puzzle from Thomas Reid faces Hume's treatment of denial. Before presenting Reid's puzzle, however, we must first get a grip on Hume's views about belief. Hume tells us this much about the nature of belief:

[T] he idea of existence is nothing different from the idea of any object, and that when after the simple conception of any thing we wou'd conceive it as existent, we in reality make no addition to or alteration on our first idea. Thus when we affirm, that God is existent, we simply form the idea of such a being...But as 'tis certain there is a great difference betwixt the simple conception of the existence of an object, and the belief of it, and as this difference lies not in the parts or composition of the idea, which we conceive; it follows that it must lie in the manner, in which we conceive it. (T.1.3.7.2; SBN 95, Hume's emphasis)

[A]s belief does nothing but vary the manner, in which we conceive any object, it can only bestow on our ideas an additional force and vivacity. An opinion, therefore, or belief may be most accurately defin'd, a LIVELY IDEA RELATED TO OR ASSOCIATED WITH A PRESENT IMPRESSION. (T.1.3.7.2; SBN 96) 
To believe that something exists and to conceive of that same thing involve the same idea. It is not as though an (imagistic!) idea of existence is tacked onto a mere conception—a faint ideaof a thing in order to yield belief in that thing's existence. Instead, a belief in a thing's existence is a lively idea that is appropriately related to a present impression. ${ }^{3}$

To defend these claims, Hume presents the following case:

Nothing is more evident, than that those ideas, to which we assent, are more strong, firm, and vivid, than the loose reveries of a castle-builder. If one person sits down to read a book as romance, and another one as a true history, they plainly receive the same ideas, and in the same order; nor does the incredulity of the one, and the belief of other hinder them from putting the very same sense upon their author. His words produce the same ideas in both; tho' his testimony has not the same influence on them. The latter has a more lively conception of all the incidents. He enters deeper into the concerns of the persons... While the former, who gives no credit to the testimony of the author, has a more faint and languid conception of all these particulars. (T.1.3.7.8; SBN 97-98)

So far, we have been presented with an intuitive, Humean picture of belief. ${ }^{4}$ But what is Hume's account of denial? Picking up on Hume's claim that the only difference between belief and mere conception is a difference in how lively the idea is, Reid advances the following dilemma against the very possibility of denial for Hume:

Take the example of the idea of a future state after death. One man believes it firmly; this means that he has a strong and lively idea of it. Another man neither believes nor disbelieves, i.e. he has a weak and faint idea. Suppose now a third 
person believes firmly that there is no life after death; I am at a loss to know whether his idea is faint or lively: if it is faint, then there can be a firm belief where the idea is faint; if the idea is lively, then the belief in a future state and the belief that there is no future state must be one and the same! (30, Reid's emphasis)

Reid assumes that, for Hume, denying a proposition ${ }_{1}$ involves having before one's mind the very same idea one would have before one's mind if one were affirming, or merely entertaining, that proposition $1 .{ }^{5}$ This is a crucial assumption to which we shall return later. But given this assumption, Reid's dilemma is damning. If denying a proposition involves having a lively idea, then - for Hume - it is impossible to distinguish denial from affirmation. After all, Hume claims that we believe something just in case the associated idea is lively in our mind's eye. On the other hand, if denying a proposition involves having a faint idea, then—for Hume—one denies a proposition just in case one merely entertains it. After all, Hume claims that we merely entertain something just in case the associated idea is faint in our mind's eye. Neither horn of this dilemma is acceptable. So Reid concludes that Hume cannot adequately treat denial. ${ }^{6}$ For the sake of explicitness, I state Reid's dilemma in premise-conclusion form below: ${ }^{7}$

1. If Hume's philosophy accommodates denial, then, for a denied proposition $p$, the idea associated with $p$ is (in the mind of the denier) either lively or faint.

2. If the idea is lively, then $p$ is affirmed, not denied.

3. If the idea is faint, then $p$ is merely entertained, not denied.

4. Therefore, Hume's philosophy does not accommodate denial. ${ }^{8}$ 
If sound, Reid's objection spells disaster for Hume. Hume's philosophy would be incompatible with anyone's denying anything. Plainly, the result that no one denies anything is absurd. So we must ask whether Reid has really forced Hume's hand. Does Hume have the philosophical resources to slip the punch of Reid's dilemma?'

I deny that Hume can overcome this dilemma. In section 2, I discuss an account of denial that it seems Hume could have accepted in order to evade Reid's dilemma. In section 3, I argue that not only is this account viciously circular, Hume instead held a different account of denial that makes him susceptible to Reid's dilemma. In section 4, I reply to the objection that Hume could have distinguished force and vivacity in order to evade Reid's dilemma. I conclude that Reid's dilemma succeeds: Hume cannot offer an adequate account of denial.

\section{A Charitable Interpretation of Hume's Views on Denial?}

\subsection{Evidence that Hume Held a Content-Contrary Account}

Reid's objection assumes that Hume accepts what Powell calls 'an Act-Contrary account of denial' (Powell, 4-5). On an Act-Contrary account, the content of a denial is the same as the content of an affirmation. I will assume that, for Hume, ideas are the contents of affirmations and denials. Figuratively speaking, an Act-Contrary account "posits both a cognitive thumbs-up and a cognitive thumbs-down. If I believe $\mathrm{C}$ and you disagree with me, I mentally give $\mathrm{C}$ the thumbsup, and you mentally give C the thumbs-down" (Powell, 6, his emphasis). Stroud describes ActContrary accounts as follows:

On [the Act-Contrary] view we have only the one idea, that of God, or of God as existing, and we can conceive it either by assenting and thereby believing that God exists, or by denying and thereby believing that God does not exist. And both 
of these "attitudes" are to be distinguished from simple conception. (75, my emphasis)

It is the assumption that Hume accepts an Act-Contrary account of denial that gets Reid's dilemma up and running. After all, the horns of Reid's dilemma concern, of a denied proposition, whether its unique content - the idea associated with that proposition — is lively or faint. This suggests that Hume, if he is to have an account of denial, must reject any Act-Contrary account. ${ }^{10}$ The alternative is to accept what Powell calls "a Content-Contrary account of denial" (Powell, 4-5). On Content-Contrary accounts, any two agents disagree about any proposition $p$ just in case one agent affirms $p$ and the other affirms $p$ 's negation. Suppose I affirm some proposition $\mathrm{C}$ but you disagree with me. Then, figuratively speaking, on a Content-Contrary account, "I stamp C with approval, [but] you do not. Instead, you stamp approval on C's opposite" (Powell, 6).

Indeed, if Hume accepts a Content-Contrary Account, then Reid's dilemma poses no threat to Hume. To ease discussion, I reproduce Reid's dilemma below:

1. If Hume's philosophy accommodates denial, then, for a denied proposition $p$, the idea associated with $p$ is (in the mind of the denier) either lively or faint.

2. If the idea is lively, then $p$ is affirmed, not denied.

3. If the idea is faint, then $p$ is merely entertained, not denied.

4. Therefore, Hume's philosophy does not accommodate denial.

Suppose, for now, that Hume accepted a Content-Contrary account. If $p$ is contingent, he should deny (3). A denied proposition $p$ may be faint and yet denied. For Hume, denying $p$-at least 
when $p$ is contingent-requires entertaining $p$ : "'Tis confest, that in all cases, wherein we dissent from any person, we conceive both sides of the question; but . . . we can believe only one" (T.1.3.7.4; SBN 95, my emphasis). On the Content-Contrary account, the proposition $p$ is not denied in virtue of the denier's having before her mind p's content - the idea associated with $p$-in a faint manner. Instead, $p$ is denied in virtue of the denier's having before her mind the content of $p$ 's negation — again, some idea — in a lively manner. To deny a proposition $p$ just is to stand in the right relation - that of affirmation - to $p$ 's negation. This is compatible with the idea associated with $p$ being faint. In fact, if one who denied $p$ had a lively idea of $p$, then (2) would entail that this agent $m u s t$ both affirm and deny $p !^{11}$

This holds whenever $p$ is contingent. If $p$ is impossible, Hume should instead deny (1). Effectively, this is to accuse Reid of advancing a false dilemma. Hume denies that we can conceive, or bring before our minds, any impossibility:

The answer is easy with regard to propositions, that are prov'd by intuition or demonstration. In that case, the person, who assents to, not only conceives of the ideas according to the proposition, but is necessarily determin' $d$ to conceive them in that manner, either immediately or by the interposition of other ideas. Whatever is absurd is unintelligible; nor is it possible for the imagination to conceive of any thing contrary to a demonstration. (T.1.3.7.3; SBN 95).

Were [a proposition] demonstratively false, it would imply a contradiction, and could never be distinctly conceived by the mind. (EHU 4.2; SBN 26)

The mind can always conceive any effect to follow from any cause, and indeed any event to follow upon another: whatever we conceive is possible, at least in a 
metaphysical sense: but wherever a demonstration takes place, the contrary is impossible, and implies a contradiction. (Abstract 13-14)

This is Hume's (in)famous thesis that conceivability entails possibility. Hume denies that we have ideas of the impossible. We cannot conceive of impossibilities. Therefore, if $p$ is impossible, no one can have an idea of it; $p$, if impossible, becomes unintelligible for Hume. ${ }^{12}$ So, (1) is not true when $p$ is impossible. This is important because we sometimes deny impossibilities.

In fact, this observation suggests to me that Hume should have held a Content-Contrary account. Given Hume's commitment to the thesis that conceivability entails possibility, only the Content-Contrary account makes sense of how we can deny impossibilities. On the Act-Contrary account, we would have to conceive of the impossible whenever we deny any impossibility. For instance, take the impossible proposition that some table is wholly red and wholly green. If Hume accepted an Act-Contrary account, denying this proposition would require having an idea of a table that is wholly red and wholly green. This idea would be the content that is denied on a Humean Act-Contrary account. But it is impossible for there to be such a table. Thus Hume should claim that we cannot conceive of such an idea. So, if Hume accepted an Act-Contrary account, he could not coherently deny that there is a table that is wholly red and wholly green. On the other hand, if Hume accepted a Content-Contrary account, then he could coherently deny that some table is wholly red and wholly green. Hume would merely have to entertain the negation 2 of this impossible proposition and affirm it 2 . (More on what it is to entertain a negation soon.) Surely, some idea is associated with the negation, since the negation is necessary. Therefore, charity seems to favor attributing a Content-Contrary account to Hume. 
Moreover, as Powell (17) notes, there is some positive textual evidence that Hume held a Content-Contrary account. Consider what Hume tells us about the philosophical relation of contrariety:

The relation of contrariety may at first sight be regarded as an exception to the rule, that no relation of any kind can subsist without some degree of resemblance. But let us consider, that no two ideas are in themselves contrary, except those of existence and non-existence, which are plainly resembling, as implying both of them an idea of the object; tho' the latter excludes the object from all times and places, in which it is suppos'd not to exist. (T.1.1.5.6; SBN 15, his emphasis)

Powell interprets this passage as suggesting the following: "Hume is positing that the only ideas standing in the relation of contrariety are those of particular existents and particular nonexistents (i.e., absences)" (Powell, 17). I assume that Hume believes some things stand in the relation of contrariety. ${ }^{13}$ Then Hume seems to have committed himself to a Content-Contrary account of denial. (Though I will dispute later this inference in section 3.) Since-for Hume-any idea of the Sun represents the Sun as existing, Hume seems to have committed himself to the claim that some other idea has a contrary content, representing the Sun as not existing. As Hume put it in the above passage, the idea of a thing's non-existence "excludes the object from all times and places, in which it is suppos'd not to exist" (T.1.1.5.6; SBN 15). ${ }^{14}$

\subsection{The Exclusion Account}

Hume's talk of exclusion suggests an intuitive account of denial: For an agent $S$ to deny a proposition $p$ is for $S$ to affirm a proposition that $S$ believes is incompatible with $p \cdot{ }^{15}$ In Humean 
terms, the proposal is that to deny a proposition $p$ is to have a lively idea that one believes is incompatible with the idea (if any) associated with $p \cdot{ }^{16}$ In a slogan: To deny is to affirm something that excludes. Call this Content-Contrary account "the exclusion account."17 Powell defends the exclusion account: ${ }^{18}$

[This view] posits what I will call relationally negative contents. That is to say, all contents are, fundamentally, positive contents, but some of them conflict with each other .... The approach starts by identifying certain positive ideas which are, in short, too crowded to include Dumbo [an example object]. As a silly example, we could consider the idea of a world that is entirely filled with chocolate pudding. Now, this idea is a positive idea of a pudding-filled world. But if we take our idea of Dumbo and compare it to this pudding-filled-world-idea, there will be a sort of conflict between them: we can't add Dumbo to the puddingworld, because every place he might go in that world is already occupied by pudding. So, this pudding-world can, in addition to being a positive idea, be an idea that conflicts with the idea of Dumbo. It is a pair of positive ideas, such that you can't believe in both of them at once. (Powell, 16, his emphasis)

To deny that Dumbo exists is to believe something — have some lively idea — that one believes is incompatible with Dumbo's existence. The idea of a pudding-world without any more room for anything else will do. Here is another example: To deny that Wittgenstein is alive is to believe something that one believes is incompatible with Wittgenstein's being alive now. The idea of Wittgenstein's death in 1951 will do. Intuitively, the exclusion account says that to deny something $_{3}$ is to believe something else that rules it $t_{3}$ out.

Powell tells us more about this Content-Contrary account: 
A natural concern about this proposal is that it might seem like believing that Dumbo doesn't exist requires believing that the world is entirely full of pudding . ... The idea of pudding-world is not the only idea that crowds out Dumbo. It is merely one example .... What would be ideal is to collect together the set of all such ideas, for use as the general idea of Dumbo's absence or nonexistence. As a sort of resemblance nominalist, Hume could really give us an account of this general idea only if there were some resemblance among all of these ideas, though. And it seems like, say, the idea of a world entirely filled with lead doesn't resemble the pudding-world in any interesting respect .... The only feature these disparate ideas will all have in common is Dumbo-exclusion. So we could group them together in respect of their relationship to Dumbo. But this is a good feature to have in our account, as it both explains how the idea of Dumbo would be related to the production of the idea of the nonexistence of Dumbo, as well as helping us see why the idea of the absence of Dumbo differs from the idea of the absence of Pegasus . . . . Some Dumbo-allowing worlds still rule out Pegasus, and some Dumbo-excluding worlds still allow Pegasus. (Powell, 16)

The idea of Dumbo's nonexistence, then, is a general idea that, as it were, contains all particular ideas incompatible with Dumbo's existence. ${ }^{19}$ To deny Dumbo's existence is to have one of these ideas in a lively manner.

The exclusion account is a natural view to attribute to Hume. ${ }^{20}$ As we saw earlier, Hume can evade Reid's dilemma if he accepts a Content-Contrary account. Moreover, it is unclear how Hume could make sense of denying impossibilities unless he accepted a Content-Contrary 
account. Finally, the exclusion account seems to make sense of what little Hume tells us about denial.

\section{Excluding the Exclusive Account Interpretation}

\subsection{Philosophical Issue: Vicious Circularity}

But not all is well, philosophically speaking. The exclusion account suffers from vicious circularity.

Recall that in Humean terms, the view states the following: To deny a proposition $p$ is to have a lively idea that one believes is incompatible with the idea (if any) associated with $p$. The key word is "incompatible." What is it for one idea to be incompatible with another? It is surely not for the conjunction of the two ideas to be metaphysically impossible. Recall Powell's example of the pudding-world and Dumbo. The idea of pudding-world and the idea of Dumbo are incompatible. But surely their conjunction is not metaphysically impossible. We can simply imagine Dumbo on top of the pudding-world. But Hume accepts that conceivability entails possibility. So, for Hume, the conjunction of the two ideas is possible, despite being incompatible in Powell's sense. ${ }^{21}$

But what if metaphysical modality is too broad? Let's see what happens if we understand incompatibility in terms of nomological modality-which concerns what is possible given the laws of nature. What if two ideas are incompatible just in case it is nomologically impossible for them to both be true? This, however, will not help. Suppose we believe that $C_{1}$

$\& \ldots \& C_{\mathrm{n}}$ describe the laws of nature. Then it is natural, given our new understanding of incompatibility, to say that believing two ideas $A$ and $B$ are incompatible is to believe $\sim((A \& B)$ $\left.\&\left(C_{1} \& \ldots \& C_{\mathrm{n}}\right)\right)$. But if both (i) I have a lively idea of $A$ and (ii) I believe $A$ and $B$ are 
incompatible, the exclusion account will still generate a viciously circular explanation of how it is I can deny $B$. (I am also assuming that none of the conjuncts in $C_{1} \& \ldots \& C_{\mathrm{n}}$ is denied. This is acceptable, since an account of denial should not rest on whether we have true beliefs about what the laws of nature are.) To see this, observe that the only way for me to believe the negation $\sim((A$ $\left.\& B) \&\left(C_{l} \& \ldots \& C_{n}\right)\right)$ is to believe $\sim B$, which just is to deny $B$ on the Content-Contrary account. Denial would be analyzed in terms of denial! In fact, this circularity objection generalizes to any gloss of incompatibility in terms of any modality that is narrower than metaphysical modality. ${ }^{22}$

Perhaps the notion of incompatibility appealed to in the exclusion account does not appeal to modality at all. Roughly, the picture is that when I believe some idea $A$, I believe that $A$ is incompatible with another idea $B$ just in case I deny their conjunction. In Humean terms, something about adding $B$ to $A$ makes me deny the resulting conjunctive idea. Assuming one strangely believes the pudding-world is actual, this picture handles Powell's pudding-world and Dumbo example well. One has a lively idea of the pudding-world, but denies that the conjunctive idea of the pudding-world and Dumbo is true. There just is no room for Dumbo, even if it is possible that there is room for Dumbo.

Incompatibility then amounts to just this: Two ideas are incompatible just in case if one is true, the other is not. Equivalently, two ideas are incompatible just in case it is false that both are true. ${ }^{23}$ Therefore, the Humean exclusion account states that to deny some idea $A$ is to have some lively idea $B$ such that one believes $\sim(A \& B) .{ }^{24}$ But on any Content-Contrary account like the exclusion account, to believe a negation (e.g. $\sim(A \& B)$ ) just is to deny that which is negated. But to deny $A \& B$, one has to - given a lively idea of $B$ - deny $A$. But we were seeking an account of how it is possible to deny $A$. Circularity rears its ugly head in once again. 
So, as long as incompatibility is not understood in terms of metaphysical modality (which would be, as discussed earlier, independently implausible), the Humean exclusion account explains denial only in terms of denial. Perhaps one will initially find this kind of circularity unproblematic, or even virtuous. After all, for instance, any theory of truth will have to appeal to truths. But the circularity here may prove more problematic. If we are seriously worried that Hume cannot give an adequate account of denial, we will be unsatisfied if the best account of denial we can attribute to him is one on which denial is understood in terms of denial. ${ }^{25}$ But we were wondering if Hume could make sense of denial at all! Analogously, a chemistry teacher may be unsatisfied, upon asking a student "What are electrons?" if the student answers "Electrons are electrons." A true answer, but one with less content than desired.

So even if Hume held the exclusion view of denial, I deny that Hume can legitimately appeal to it. In the next section, however, I argue that this dispute is orthogonal to Hume interpretation. Hume imprudently accepted an Act-Contrary account of denial. If so, he is impaled on both horns of Reid's dilemma.

\subsection{Interpretative Issue: Disbelief, Incredulity, and Fiction}

In section 1.3.7 of the Treatise, Hume resolves to determine "[w] herein consists the difference betwixt incredulity and belief" (T.1.3.7.3; SBN 95, his emphasis). ${ }^{26}$ Hume then immediately proposes the following answer:

We may mingle, and unite, and separate, and confound, and vary our ideas in a hundred different ways; but till there appears some principle, which fixes one of these situations, we have in reality no opinion: And this principle, as it plainly makes no addition to our precedent ideas, can only change the manner of our 
conceiving them .... So that as belief does nothing but vary the manner, in which we conceive any object, it can only bestow on our ideas an additional force or vivacity. (T.1.3.7.4-5; SBN 96, his emphasis)

To answer the question of how to distinguish belief from disbelief, Hume speaks only of varying force and vivacity. This suggests that, for Hume, contrary beliefs and denials share a common content. Just shift the liveliness of the idea, and you may go from belief to denial (or vice-versa). But this is entirely incompatible with a Content-Contrary account of denial.

Indeed, if Hume held a Content-Contrary account of denial, one would expect him to have said something about how the contents of belief and denial differ here. ${ }^{27}$ After all, it is in section 1.3.7 of the Treatise that Hume tasks himself with determining "the difference betwixt believing and disbelieving a proposition ... [or] the difference bextwixt incredulity and belief' (T.1.3.7.3; SBN 95, his emphasis). Interpretatively speaking, such a gross omission seems best explained as no omission at all. That is, a complete lack of discussion of the differing contents of belief and denial suggests that Hume did not hold a Content-Contrary account. ${ }^{28}$

Moreover, the Treatise provides positive textual evidence that Hume accepted an ActContrary account of denial:

An idea assented to feels different from a fictitious idea, that the fancy alone presents to us: And this different feeling I endeavor to explain by calling it a superior force, or vivacity, or solidity, or firmness, or steadiness. This variety of terms... is intended only to express that act of the mind, which renders realities more present to us than fictions .... And in philosophy we can go no farther, than assert, that it is something felt by the mind, which distinguishes the ideas of the judgment from the fictions of the imagination. (T.1.3.7.7; SBN 629, his emphasis) 
I take it that Hume is aware that we often imagine patent falsehoods. I am imagining a dragon flying over my home now, but it is patently false that a dragon is flying over my house right now. So, I deny that a dragon is flying over my house right now. But in the above passage, Hume seems to be telling us that, in general, the difference between the ideas we believe and fictitious ideas is merely a feeling. And this feeling is that of having a more or less lively, or vivid, idea. The most natural way of interpreting Hume here is to attribute an Act-Contrary account of denial to him. On such an account, the difference between belief and denial is a difference in the liveliness of an idea. On this picture, my denying that a dragon is flying over my house right now just is my having an idea of such a dragon with the appropriate liveliness.

But if we are to attribute an Act-Contrary account to Hume, we must reply to Powell's (17) claim that textual evidence supports the contrary conclusion, that Hume held a ContentContrary account. In particular, we have to make sense of the following passage:

The relation of contrariety may at first sight be regarded as an exception to the rule, that no relation of any kind can subsist without some degree of resemblance. But let us consider, that no two ideas are in themselves contrary, except those of existence and non-existence, which are plainly resembling, as implying both of them an idea of the object; tho' the latter excludes the object from all times and places, in which it is suppos'd not to exist. (T.1.1.5.6; SBN 15, his emphasis)

This passage in fact indicates that Hume (incautiously!) held an Act-Contrary account. In this passage, Hume tells us that our ideas of existence and non-existence plainly resemble each other. This is straightforward on a Humean Act-Contrary account. On such an account, the idea of Dumbo's existence and the idea of Dumbo's non-existence are both ideas of Dumbo. They simply differ in their degree of liveliness or vivacity. As both are ideas of Dumbo, they 
straightforwardly resemble one another; they straightforwardly "imply . . . an idea of the object" (T.1.1.5.6; SBN 15).

But on a Humean Content-Contrary account, it is dubious that the idea of Dumbo's nonexistence resembles the idea of Dumbo. Recall Powell's pudding-world example. Does the idea of pudding-world resemble the idea of Dumbo? It does not. Certainly, they do not "plainly resembl[e]" (T.1.1.5.6; SBN 15). Moreover, the exclusion account's appeal to a general idea of Dumbo's non-existence does not help. Does the general idea of a triangle resemble Dumbo? No. After all, none of them implies, or suggests to the mind, the idea of Dumbo. But the same holds of particular ideas that exclude Dumbo. Just as an idea of a point-sized world does not imply the idea of Dumbo, the idea of pudding-world does not imply the idea of Dumbo.

The only interpretative issue is that attributing an Act-Contrary account to Hume does not readily account for his offhand remark that the idea of an object's non-existence "excludes the object from all times and places, in which it is suppos'd not to exist" (T.1.1.5.6; SBN 15). From the point of view of the Act-Contrary account, this suggests a comical image in which the nonexistent reside in a faraway Meinongian jungle, a place where the nonexistent live. ${ }^{29}$ Nothing there really exists. (Meinongianism is the view that there are nonexistent things.) ${ }^{30}$

Perhaps we are not forced to attribute such a strange view to Hume. If Hume really believes in an Act-Contrary account, then to have an idea of Dumbo with the appropriate liveliness just is to deny Dumbo's existence. If so, then some ideas of Dumbo-ideas of Dumbo's non-existence - exclude Dumbo from the times and places in which he is supposed not to exist. 
Here, one might object that, for Hume, any idea of any object represents it as existing. Therefore, would it not be odd if, for Hume, denying the existence of something required having a faint idea of that object? This idea, even faint as it is, would represent it as existing.

This should be no obstacle to attributing an Act-Contrary account to Hume. After all, on an Act-Contrary account, denying an idea does not involve affirming anything about the denied idea. On such an account, to deny that the sky is green, one conjures up before one's mind a faint idea of the sky's being green. By doing so, one does not affirm that the sky is green, even though the idea she has before her mind — the (faint) idea of the sky's being green—does represent the sky as being green. Things are no different with existence. On an Act-Contrary account, I may deny that Pegasus exists by having before my mind a faint idea of Pegasus, even though any idea of Pegasus represents Pegasus as existing.

I have nothing else to say in way of textual interpretation of Hume. But if I am right that Hume accepted an Act-Contrary account, then he is in philosophical trouble. As Reid's dilemma shows, Hume would be unable to distinguish denial from outright belief or mere conception.

\subsection{Other Propositional Attitudes}

If Hume does hold an Act-Contrary Account, Stroud seems right to point out that things get even worse for Hume:

It is clear that, once we think not just about belief and conception, but about all the rest of the great variety of "attitudes" we can take with respect to a single idea, there is no plausibility at all in saying that they differ only in their degrees of force and vivacity. For any idea representing some state of affairs $p$, we can conceive of or contemplate what it would be like if $p$ obtained, imagine that $p$ 
obtains, hope that $p$ obtains, wonder whether it obtains, ask whether it does, believe that $p$ obtains, and so on. But there is no temptation to suppose that wondering or asking is just conceiving something more faintly or more weakly than believing it. (Stroud, 75-76)

Indeed, Hume's problem with denial seems to just be an instance of broader problem with the propositional attitudes. Force and vivacity simply do not suffice to adequately treat them all.

In fact, the problem for Hume is more acute with some of the propositional attitudes other than denial. For example, take the propositional attitude of wondering. I can wonder about that which I believe. After all, I recognize that I am not infallible. To take an example, consider my idea of sunshine in Saint Petersburg, Florida. It is barely a lively idea. That is, I believe that it is sunny in Saint Petersburg right now, but I am not very confident that this is so. Even though I believe it is sunny, I wonder whether it is so. But it is patently false that whenever I have an idea that is barely lively, I wonder whether it is veridical. Suppose I have a barely lively idea that the number of trees in Florida is even. Perhaps a biologist reported to me that the number of trees in Florida is even. (But I do not trust her testimony very much.) As I do not care whether or not the number of trees in Florida is even, I do not wonder whether this really is so. The question of whether this is so simply does not arise for me. This is a case of a barely lively idea without wonder.

So, wondering cannot be captured merely in terms of force and vivacity. Hume, however, is committed to claiming that it can. Hume, being all too Humean, has unnecessarily constrained his philosophical theorizing. He needs more than force and vivacity to do justice to the propositional attitudes. 


\section{A Reply From Force and Vivacity?}

\subsection{A Proposed Distinction}

Let us consider an objection to Reid's dilemma. A defender of Hume might concede that Reid's dilemma is compelling if Hume's notions of force and vivacity are univocal, understood intuitively as the crispness or clarity of ideas. However, following Trudy Govier, a defender of Hume might insist that force and vivacity should be thought of as distinct. ${ }^{31}$ Besides their relative crispness, ideas may also differ in their "influence upon other ... ideas" (Govier, 48). Ideas have different capacities to influence which ideas will arise in the minds of their possessors thereafter. For example, a crisp idea of having lost all my savings in a night of gambling would be more influential on succeeding ideas than a crisp idea of my having eggs for breakfast.

Govier calls the crispness of an idea its vivacity, and the influence of an idea upon other ideas its force. Given this distinction, Hume may be able to resist Reid's dilemma. Perhaps all Hume would have to do is to insist that the difference between a believed idea and a denied idea lies in the difference between their respective forces. If I believe that there is a fire in my home, I will be likely to later have before my mind grim ideas of my house burning down or even my death. On the other hand, if I deny that there is a fire in my home, then I will likely later have before my mind the idea of my sleeping peacefully in my bed. Crucially, this can be so even if the ideas associated with believing and denying that my house is on fire are both ideas of my house on fire. They may even be equally vivid; on the proposal being considered here, their essential difference lies in their respective forces.

As Govier (47) notes, the following passage from the Treatise suggests that Hume implicitly accepted a distinction between force and vivacity: 
A poetical description may have a more sensible effect on the fancy, than a historical narration. It may collect more of those circumstances, that form a compleat image or picture. It may seem to set the object before us in more lively colours. But still the ideas it presents are different to the feeling from those, which arise from the memory and the judgment. There is something weak and imperfect amidst all that seeming vehemence of thought and sentiment, which attends the fictions of poetry. (T.1.3.10.10; SBN 631, my emphasis)

Govier suggests that “[w]e might sum up Hume's point here by saying that ideas conveyed by poetry may be very vivid, but are not very strong [or forceful]—-we do not take them to be true and, accordingly, they do not affect our other ideas as do the ideas of memory and judgment" (47). This seems to not be an unreasonable interpretation of the above passage from the Treatise.

I have two objections, one philosophical and one interpretative, against using a distinction between force and vivacity in order to save Hume from Reid's dilemma.

\subsection{Philosophical Objection: A Forceful Analogue of Reid's Dilemma}

First, if we grant the distinction between force and vivacity, we may reproduce an analogue of Reid's dilemma, but for forcefulness instead of vivacity:

$1^{*}$. If Hume's philosophy accommodates denial, then, for a denied proposition $p$, the idea associated with $p$ is (in the mind of the denier) either forceful or not.

$2^{*}$. If the idea is forceful, then $p$ is affirmed, not denied.

$3^{*}$. If the idea is not forceful, then $p$ is merely entertained, not denied.

4*. Therefore, Hume's philosophy does not accommodate denial. 
The only questionable premise here is $\left(3^{*}\right)$. And indeed, it may raise eyebrows. However, if premise (3) — which is just $\left(3^{*}\right)$ with "faint" or "not vivid" substituted for "not forceful"—of Reid's original dilemma is plausible, then $\left(3^{*}\right)$ may also seem plausible by parity of reasoning. Originally, we were working with the assumption that affirmed or believed ideas were vivid, and so merely entertained ideas were not vivid. But it is unclear why things would be any different once we replace vivacity with forcefulness. Merely entertained ideas can clearly be unforceful. Suppose I am agnostic about whether or not there is an even number of dogs in Portland, Oregon. Suppose, moreover, that I entertain the idea that there is an even number of dogs there. This idea will not have much, if any, effect on the series of succeeding ideas that come before my mind. Intuitively, it does not matter to me whether or not there is an even number of dogs in Portland, Oregon. It is not at all forceful. Yet, I merely entertain it, neither believing nor denying it.

At this juncture, a natural maneuver by a defender of Hume would be to insist that denied ideas are always less forceful than merely entertained ideas. If so, then along the scale of forcefulness, there are three divisions. Believed ideas would be the most forceful. Denied ideas would be the least forceful. Merely entertained ideas would be in the middle. If merely entertained ideas - and thus denied ideas too - are not considered forceful, this would entail the falsehood of $\left(3^{*}\right)$.

But this is to throw out the baby with the bathwater. I reject the proposed division of labor. Some merely entertained ideas are less forceful than some denied ideas. For example, consider the denied idea that I will painfully die the next time I drive. While I deny this idea, the cost of being wrong is so high that I may-especially if I am prone to fits of paranoia-begin 
entertaining all sorts of ideas about how driving could go badly or how one could die in the normal course of life. That is, even if I deny the idea that I will painfully die the next time I drive, this idea can nonetheless be forceful. (If it helps, suppose I hold a small but non-zero credence that I will die painfully the next time I drive. Nonetheless, I can deny this proposition. Surely I do not need to be certain that a proposition is false in order to deny it.) Now compare the forcefulness of this idea with that of the merely entertained idea that there is an even number of dogs in Portland, Oregon. This latter idea is not at all forceful. Since any forceful idea is more forceful than any unforceful idea, it follows that the denied idea of my painfully dying the next time I drive is more forceful than the merely entertained idea of there being an even number of dogs in Portland, Oregon. Therefore, some merely entertained ideas are less forceful than some denied ideas.

And it should be even more obvious that some denied ideas are less forceful than some merely entertained ideas. ${ }^{32}$ Even if we reject $\left(3^{*}\right)$ on the grounds that some unforceful ideas are denied ideas, we must still recognize that denial cannot be theorized about solely in terms of forcefulness. Hume cannot give an adequate account of denial solely in terms of the forcefulness of ideas.

What of giving an account of denial in terms of both vivacity and forcefulness? I take it that the only two viable options are conjunctive and disjunctive, respectively, in nature. But neither is acceptable.

The conjunctive account says that an idea is denied if it is neither vivid nor forcefulthat is, if it is both not vivid and not forceful. However, this account of denial is too weak. Just consider once again the forceful idea that I will painfully die the next time I drive. Since it is 
forceful, it fails to be jointly not forceful and not vivid. (It does not matter if it is vivid or not.) And yet, I deny this idea. Therefore, the conjunctive account is false.

The disjunctive account says that an idea is denied if it is either not vivid or not forceful. However, this account is too strong. Just consider once again the unforceful idea that there is an even number of dogs in Portland, Oregon. Since it is not forceful, it is not forceful or not vivid. But I merely entertain the idea that there is an even number of dogs in Portland, Oregon. I am agnostic as to its truth. Hence, I do not deny it. Therefore, the disjunctive account is false.

Not only is it impossible to give an account of denial solely in terms of forcefulness, it is also impossible to give an account of denial in terms of both forcefulness and vivacity.

\subsection{Interpretative Issue: Hume Sees No Distinction}

In any case, it seems Hume understood force and vivacity to amount to the same thing. In the Appendix to the Treatise, Hume explicitly states that he uses "vivid," "forceful," and the other words he uses to describe the feeling of believed ideas synonymously: ${ }^{33}$

And this different feeling I endeavour to explain by calling it a superior force, or vivacity, or solidity, or firmness, or steadiness. This variety of terms, which may seem so unphilosophical, is intended only to express that act of the mind, which renders realities more present to us than fictions .... Provided we agree about the thing, 'tis needless to dispute about the terms (T.1.3.7.7; SBN 629, his emphasis)

Hume is here explicitly telling us that, for him, there is only one significant dimension, with respect to belief, along which ideas can differ: force, vivacity, solidity, firmness, or steadiness. 
We should take him at his word. It is then not available to Hume to account for denial using distinct notions of vivacity and forcefulness.

\section{Conclusion}

I have ultimately argued for a pessimistic conclusion: Hume falls victim to Reid's dilemma. Hume thus cannot account for denial. I have sketched what I take to be the account of denialthe exclusion account - that (i) evades Reid's dilemma and (ii) is most friendly to Hume's philosophy. However, not only is there some reason to suspect that the exclusion account is circular, but Hume did not in fact hold it. He should have embraced the exclusion account. But he did not. Moreover, I have shown that Hume cannot avoid Reid's dilemma by appealing to a distinction between force and vivacity. I conclude, then, Reid's objection to Hume's account of denial is successful. Hume cannot deny Reid's dilemma. ${ }^{34}$

\section{NOTES}

${ }^{1}$ Hume's work is cited as follows: References to the Treatise are to Hume, A Treatise of Human Nature, ed. Norton and Norton, hereafter cited in the main text as " $\mathrm{T}$ ” followed by Book, part, section, and paragraph number, and to Hume, A Treatise of Human Nature, ed. Selby-Bigge, rev. by Nidditch, cited in the text as "SBN" followed by the page number. References to the Enquiry are to Hume, An Enquiry concerning Human Understanding, ed. Millican, hereafter cited in the main text as "EHU" followed by section and paragraph number, and Hume, An Enquiry Concerning Human Understanding, ed. Selby-Bigge, rev. by Nidditch, hereafter cited in the text as "SBN" followed by page numbers. References to the Abstract of a Treatise of Human Nature are to Hume, An Abstract of a Treatise of Human Nature, hereafter cited in the main text as "Abstract" followed by page numbers.

${ }^{2}$ That is, disjunction, the material conditional, and the material biconditional can be defined in terms of conjunction and negation. 
${ }^{3}$ Though Hume (T.1.3.8; SBN 98) has much to say about what it is for an idea to be appropriately related to a present impression, I put this qualification — that a belief be appropriately related to a present impression — aside in the future. Nothing of significance in this paper rests on it. But it is noteworthy that "although [Hume's] wording in both the Treatise and the Enquiry suggest that he is giving an account of belief per se, he is in fact doing something far more restricted. Specifically, he is providing us with an analysis of those beliefs that result from our experience of past conjunctions" (Jenkins, 80). Even so, as Jim Van Cleve has suggested to me, it seems Hume is wrongly bringing a cause of such belief — present impressions — into a definition of belief. But causes of $x$ need not, and usually should not, appear in a definition of $x$.

${ }^{4}$ I say intuitive, not uncontroversial. Stroud claims that "whatever the difference might be [between believing something and taking it to be fictitious], it is clear that Hume has not captured it here. What he says is completely untrue in every respect .... This looks like a clear case of Hume's denying the obvious" (71-72).

${ }^{5}$ Here, subscripts are used in order to make the reference of "that proposition" unambiguous.

${ }^{6}$ Reid does not consider the possibility that denying a proposition is nothing more than failing to have the associated idea before one's mind, but this is an understandable exclusion. This proposal is wildly implausible. It would entail the absurd result that whenever I fail to have an idea of any tree before my mind, I deny that trees exist. Moreover, suppose that Ann has never seen or heard of snow. Suppose further that Ann has never wondered whether snow exists. She has never had the idea of snow before her mind. Then, on the proposal being considered here, Ann (automatically) denies that snow exists. But surely this is an absurd result. Ann might very well remain agnostic as to snow's existence.

${ }^{7}$ I understand premises (1)-(3) schematically, with $p$ as a variable ranging over denied propositions. I am also taking "the idea" in (2) and (3) to be anaphoric on "the idea associated with $p$ " in (1). This makes the presentation of the argument in the main text simpler without, I believe, adding any substantial confusion.

${ }^{8}$ Strictly speaking, the inference from (1)-(3) to (4) is invalid. The inference is valid only if the following assumption is added: Some propositions are denied. I take it, however, that this assumption is obviously true. Therefore, for all intents and purposes, (1)-(3) entail (4). 
${ }^{9}$ Dorsch (2016) points out a more fundamental problem for a Humean account of denial: Any such account fails to accommodate how "the contents of thought differ in kind from the contents of experience. For example, thought contents are subject to propositional logic, but sensory contents are not. If we are able to think that $p$ or $q$, then we are also able to think their negation .... But we cannot see the negation of a green tree (which is not the same as not seeing a green tree, or seeing a red tree)" (48). The problem arises from Hume's putting ideas to a dual purpose: For Hume, ideas are both the objects of thought as well as (mental) perceptions. I am sympathetic with Dorsch's worry, but I will put it aside so as to focus on Reid's dilemma.

${ }^{10}$ Moreover, Powell (6-11) provides several independent reasons why Hume should reject Act-Contrary accounts of denial.

${ }^{11}$ Note that there is no necessary connection between the contingency of a proposition and its liveliness. A contingent proposition can be either lively or faint. If I firmly believe that my shirt is red, then my idea of my shirt's being red is lively. On the other hand, if I am unsure whether my shirt is red (perhaps I put it on haphazardly this morning and did not attend to its color all day), then my idea of my shirt's being red is faint. But in either case, whether my idea of my shirt's being red is lively, this idea is contingent. After all, I can easily conceive of my shirt's being red and I can easily conceive of my shirt's not being red. I can, for instance, imagine that my shirt is wholly blue.

${ }^{12}$ I will thus put aside the case where $p$ is necessary. For Hume, we would be acting incoherently-nonsensically even - in denying a necessary proposition. For Hume, we cannot even imagine a necessary proposition's being false.

${ }^{13}$ If not, why would Hume mention the philosophical relation of contrariety at all so early on in the Treatise?

${ }^{14}$ Powell (17-18) argues that there is other textual evidence that Hume accepts a Content-Contrary account, but I find this other textual evidence to be tenuous. Hume's direct statement on the relation of contrariety, it seems to me, provides the strongest textual evidence.

${ }^{15}$ The qualification that $S$ believes the idea in question is incompatible with the idea associated with $p$ seems necessary. It really is incompatible with Wittgenstein's being alive now that he died in 1951. But if I believe Wittgenstein was recently resurrected, then I do not deny that Wittgenstein is alive now when I have a lively idea of 
Wittgenstein's death in 1951. In such a case, I believe the two relevant ideas to be compatible. Belief in incompatibility—not incompatibility simpliciter — therefore seems to be what is necessary for denial.

${ }^{16}$ The proviso "if any" is necessary because if $p$ is impossible, Hume will not grant that there is an idea associated with $p$. If $p$ is impossible, then I take it that—for Hume—having any lively idea whatsoever suffices to deny $p$.

${ }^{17}$ In personal conversation, Jim Van Cleve suggested to me an alternative Humean account. On this alternative account, a negated proposition just is a proposition with a negation operator, or, in informal imagistic terms, a red circle with a slash through it. But this cannot be Hume's view, since there is no simple impression from which to derive the idea of this negation operator. One does not have simple impressions of negation operators. And if the idea of the negation operator is supposed to be complex, from which simple impressions could its parts be copied? We never literally sense the parts of a logical operator.

${ }^{18}$ Powell (14n33) attributes the view to Don Baxter and Don Garrett, who suggested the view to Powell in personal conversation.

${ }^{19}$ This parallels Hume's (T.1.1.7.10; SBN 22) treatment of other general ideas.

${ }^{20}$ Powell (15) develops another Content-Contrary account that he considers attributing to Hume. On this account, we perceive absences. An idea of my office without my keys is not only an idea of my office, but an idea of the absence of my keys. To generalize this account, to deny something is to have an idea of its falsity. In the case of negative existentials, one sees the absence of thing in question in any lively idea one has. While this is an interesting view, it suffers from what I take to be devastating interpretive and philosophical problems; Powell (20) discusses these problems. For this reason, I put this alternative Content-Contrary account aside in the main text.

${ }^{21}$ One might insist that we cannot imagine Dumbo inside of the pudding world since Powell stipulates that there simply is not enough room to fit Dumbo in this world. If this is right, then perhaps it is metaphysically impossible for Dumbo to be in the pudding world. However, I deny the premise that we cannot imagine Dumbo inside of the pudding world. We might just have to imagine that the laws of nature are different. Or, if one is convinced that the laws of nature are metaphysically necessary, one can imagine that pudding is less dense than it actually is. Or, if one believes that pudding's density is essential to it, one can imagine that the pudding world's borders would expand just enough to fit Dumbo if he were to appear in it. The burden of proof is on a defender of the exclusion account to say 
why all of these circumstances - and any other circumstances that would make room for Dumbo in the pudding world — are inconceivable. For encouraging me to discuss this potential worry, I wish to thank Lewis Powell and an anonymous reviewer from Hume Studies.

${ }^{22}$ Thanks to a helpful reviewer for encouraging me to discuss whether modalities weaker than metaphysical modality could enter into the exclusion account's understanding of incompatibility.

${ }^{23}$ The following is a classical theorem: $((\mathrm{A} \rightarrow \sim \mathrm{B}) \&(\mathrm{~B} \rightarrow \sim \mathrm{A})) \leftrightarrow \sim(\mathrm{A} \& \mathrm{~B})$.

${ }^{24}$ Initially, I worried that this result would lead to a vicious regress. After all, on the exclusion account, to deny ( $A$ \& $B$ ) just is to deny, for some lively idea $C,(A \& B \& C)$. But to deny this would involve denying another, even bigger, conjunction. But this regress now strikes me as benign. To deny all these conjunctions at once, one just needs to deny $B-$ a conjunct common to all these conjunctions. One denial unproblematically generates all the denials posited.

${ }^{25}$ For this reason, it would be unacceptable for Hume to take exclusion to be primitive. Of course negation can be understood in terms of exclusion - the notion of exclusion is already so similar to the notion of negation. Moreover, an account of negation in terms of a new primitive, exclusion, will prevent Hume from achieving his ambitious plans to understand belief and denial solely in terms of impressions, ideas, and their force and vivacity.

${ }^{26}$ In the third edition to Bailey's celebrated An Universal Etymological English Dictionary (1726), which was the most popular English dictionary of the $18^{\text {th }}$ century, "incredulity" is defined as "Unbelief, Unaptness or Backwardsness to Believe." Notably, "incredibility"- which derives from the same Latin word (incredulus) as “incredulity"-is defined as "being incredible, or past Belief." Hume did not publish the Treatise until 1738.

${ }^{27}$ Here, I am rejecting Powell's (18) claim that the lack of explicit discussion of denial in Hume indicates that Hume held a Content-Contrary account. Rather, the lack of such discussion is indicative of his holding an Act-Contrary account.

${ }^{28}$ Stroud (75) makes this very point.

${ }^{29}$ I say this despite being sympathetic to Meinongianism, but that is another matter. What is important is that Hume clearly rejects Meinongianism. Any idea of any object, for Hume, represents that object as existent.

${ }^{30}$ Meinong defends Meinongianism in order to account for singular thought about nonexistent objects. 
${ }^{31}$ Govier does not discuss Reid's dilemma. But, as I will soon discuss, the distinction she makes between force and vivacity may seem appealing to a philosopher who wishes to defend Hume against Reid's dilemma.

${ }^{32}$ For instance, consider the denied idea that tomatoes are vegetables and the merely entertained (at the time of submitting this paper) idea that this paper is published in Hume Studies. The former is unforceful. The latter is forceful.

${ }^{33}$ Govier recognizes this: "As Hume himself reports in the Appendix, he ... would not have made the distinction between the force of an idea and its vivacity" (46).

${ }^{34}$ For helpful conversations on the topic of this paper, I thank David Clark, Troy Cross, Jeremy Goodman, John Hawthorne, Laura Nicoară, and Weng Kin San. For helpful comments on the paper, I thank Lewis Powell, Nick Zangwill, and two anonymous reviewers from Hume Studies. Most of all, however, I wish to thank Jim Van Cleve. Jim gave insightful comments on two early drafts of this paper and taught me almost everything I know about Hume.

\section{WORKS CITED}

Bailey, Nathan. A Universal Etymological English Dictionary, $3^{\text {rd }}$ ed. London, 1726.

Dorsch, Fabian. "Hume," in The Routledge Handbook of Philosophy of Imagination. Edited by Amy Kind, 40-54. London: Routledge, 2016.

Govier, Trudy. "Variations in Force and Vivacity in Hume." The Philosophical Quarterly 22.86 (1972): 44-52.

Hume, David. An Abstract of a Book Lately Published; Entitled, A Treatise of Human Nature $\& c$. Wherein the Chief Argument of that Book is Farther Illustrated and Explained. London, 1740.

Hume, David. A Treatise of Human Nature. Edited by Amherst Selby-Bigge and P.H. Nidditch. Oxford: Oxford University Press, 1978. 
Hume, David. A Treatise of Human Nature. Edited by David Fate Norton and Mary J. Norton. Oxford: Oxford University Press, 2007.

Hume, David. An Enquiry Concerning Human Understanding. Edited by Peter Millican. Oxford: Oxford University Press, 2007.

Hume, David. An Enquiry Concerning Human Understanding and Concerning the Principles of Morals ( $3^{\text {rd }}$ Edition). Edited by Amherst Selby-Bigge. Revised by P.H. Nidditch. Oxford: Oxford University Press, 1975.

Jenkins, John J. Understanding Hume. Edited by Peter Lewis and Geoffrey Madell. Edinburgh: Edinburgh University Press, 1992.

Meinong, Alexius. "The Theory of Objects," in Realism: The Background of Phenomenology. Edited by Roderick Chisholm. Translated by Issac Levi, D.B. Terrell, Roderick Chisholm, 76-117. Glencoe: Free Press, 1960.

Powell, Lewis. "Hume's Treatment of Denial in the Treatise." Philosopher's Imprint 14.26 (2014): 1-22.

Reid, Thomas. An Inquiry Into the Human Mind. Edited by Derek R. Brookes. Edinburgh: Edinburgh University Press, 1997.

Stroud, Barry. Hume. London and New York: Routledge, 1977. 